\title{
Paweł Pasieka
}

(Warsaw University of Life Sciences; Department of Education and Culture)

1.

These days, landscape is not equated with the art of landscape, and therefore is not reduced to its visual aspect. This does not mean, however, that there are no circumstances under which it could be aesthetically experienced. Indeed, until recently, the aesthetic approach thrived. Mass tourism, the emphasis on the pictorial and the often-superficial nature of the corresponding experiences all reinforced this understanding and accompanying sensory reception. Viewed from a safe distance, adjusted to cater to the mass audience, captured in countless photographs or equally countless Landschaften, landscape became merely a beautiful view. Today, however, other modes of understanding and experience are available. Landscape is essentially a heteronomic phenomenon, for at least two complementary reasons. Firstly, the notion of landscape denotes not only natural surroundings but any kind of scenery with both natural features as well as man-made elements. Ever since Baudelaire's manifesto, one can even eulogize an urban landscape which is devoid of even a "trace of vegetation" or enjoy the existence of its late-modern, hyper-realistic incarnations, yet that does not mean that the landscape lacks a broader natural context. In the most general sense, landscape in nothing other than a "face of the Earth". It is every kind of surface which has been shaped by the forces of nature and human endeavour. With such a perspective on inquiry, landscape is tantamount to surroundings, environment or-in the broadest sense-the geosphere and biosphere of our planet. The approach I am suggesting may be too broad, causing the analyses and the studies devoted to it to lose focus and specificity. Secondly, despite their initial successes, both the scientistic and the semiological approaches appear to have proven insufficient when one has sought to grasp the phenomenon of landscape. The scientistic vision in which landscape was a self-contained world of physical bodies governed by natural causality feels all too limited. Apart from physical and chemical properties of living and inert features, "cultural elements" should also be discerned in landscape. In contrast, semiological analysis of landscape as a system of signs is encumbered with a corresponding flaw: human life and its environ is not just a matter of a system encoding meanings and senses of the constituents of human life. A third approach, transcending both the aforementioned, may be found in the idea advanced by Timothy Ingold, where landscape 
is identified with habitation and the social practices which affect the shape and character of the surroundings. From this standpoint, it is extremely important not to reduce landscape to a background against which our lives and the lives of other creatures takes place. On the contrary, it is a place of dynamic and reciprocal interaction between humans, plants, animals, substance and natural forces. If the term were not as multivocal, carrying such a historical baggage, and ultimately unclear, one could say that landscape stands for life. Beginning with this position-which seems one of the most interesting and rich research approaches-the crucial issues are to elucidate the structure, functions and co-dependencies between natural systems and those produced by human hand. Another, equally vital problem is the realization of the degree to which we are dependent on various environments in which we live. This is not a straightforward matter, as most people remain in contact with a living nature which has been substantially pre-processed and objectified. We know that we are a part of nature, but the experience of being a part of nature is not internally alive with us, nor is it cultivated in many contemporary societies. Being a part of nature is one thing, but it is infinitely more important to comprehend the relationships and dependencies which bind us to nature: microorganisms, insects, animals and plants. The experience of landscape has become an even more complex issue due to the fact that the networks of chains of cause and effect generated by our social practices are so tangled-becoming so remote from us-that the immediate impact of our practices on the environment and the quality of our lives is not felt (apart from occurrences man-made disasters). Carus understands the experience of landscape as a remedial measure. However, the point is not to overhaul what he claimed are "artificial forms of thinking and social practices". Instead, we should change or reject those forms and practices which reduce and diminish the significance and presence of the experience of nature in human life or directly threaten this presence. Not to return, of course, to some "natural state", to proto-societal and pre-civilizational forms of living-in other words advocating a naturalization of human existence. That would be as naïve as hoping for a future world where people lived surrounded by plastic trees and virtual spaces. Our experience of landscape requires not only that we become aware of the "forgotten context of our life" or introduce notions and categories describing links and relations with nature into our conversations; it requires, above all, an understanding of that the network of interactions which connects humans, animals and other organisms. This does not merely mean being eco-friendly. In my opinion, our comprehension of the environment-and therefore of our awareness that we are its inhabitant-is not measured solely by the extent and abundance of networks we are aware of and consider in our actions.

As Steven Pinker put it, it is a shame that when designing a space in which to live, we know so little about the needs and preferences moulded in the course of evolution. Just as our inclination for being in the company of animals and plants 
is expressed through biophilia - to use the term coined by Edward O. Wilson-so our predilections and satisfactions (also aesthetic ones) are measured by the extent to which the space of human life and its shapes (in architecture, urban planning and landscape design) tally with our evolutionarily developed preferences.

\section{2.}

For Humboldt, and especially for certain of the Romantics, only art and poetry can accomplish the task of depicting the entirety of human life in a world deprived of magic and shattered by science. While in science the fullness of nature is not articulated or becomes impossible to express, art has the capacity to express nature, to speak of the "form of heaven and earth" that belong to humankind. Although the industrial attitude to nature in the $19^{\text {th }}$ century effectively dispelled such approaches and hopes-and post-industrial societies also failed to shake of the pressure of alienation-Darwinian revolution and the development of contemporary evolutionary biology caused us to perceive a profound kinship with other species inhabiting the planet, not only on a cellular but also on a genetic and behavioural level. Gradually, we shed the prejudices and begin to understand the behaviours of other animals as well as their skills and abilities better. We have discovered sophisticated ways in which plants communicate, gained insight into their abilities and methods of fighting off pests. Advancements in ecology bring about better comprehension of the complex dependencies between particular organisms and environment, dependencies which go way beyond the simple circulation of matter and trophic chains. Perhaps knowledge will not lead to a conciliation of humans and non-humans in a social and cosmic dimension, but the world in which we live may be improved. Will, therefore, sciences rather than humanities play the leading role in studies into landscape? If, as stated above, landscape is understood primarily as habitation, then it must not be forgotten that its forms are also shaped by social forces, in which humanities do have a share. What then will their contribution be? Firstly, particularly from the standpoint of my own discipline, philosophy, it must be admitted that not all possible conclusions have been drawn from Darwinism, contemporary biology and ecology. We know that organisms evolve and that they are not immutable. We know that the finalistic, purposive vision of the world is untenable. We also know that the use of tools and communication systems is not the exclusively domain of humans. Observations have already influenced our religion, the treatment of other animals as well as our own understanding of the world and our place in it. More effort is required to draw further conclusions from the achievements of the biological sciences. Secondly, if culture is a modelling system and the humanities are an "element" which is peculiar enough to play a threefold role in it, namely that of: I) analyser (instrument of analysis), II) a comparative tool in historical and intercultural cross-sections and 
III) a modulator of social change (culture-building force), then the humanities face critical analysis of our practices, the task of enriching our language with notions and metaphors, of portraying (in the sense of Bachelardian poetics of space) our experiences of things, places and surroundings. Thirdly, from the standpoint of the aesthetics of everyday life, the humanities are destined to describe the microworlds of social practices forged as we engage in relations with objects, living organisms (plants and animals) and other people-as well as to express the bonds connecting all of the aforementioned.

\section{3.}

In view of the fact that landscapes are made up of such distinct ontological entities as plants, animals, microorganisms, humans, earth, rocks, concrete, glass, aesthetic preferences, the environmental demands of organism, relations between elements of ecosystems, texts about landscape and positions defining the rules of its planning and management, as well as texts about those texts etc.-an interdisciplinary approach is in a sense a natural milieu of landscape studies. One could, of course, analyse landscape from a particular, specialist perspective, though even then always with the awareness of limitations that such a perspective entails. There are so many disciplines in which landscape analyses are undertaken that all kinds of alliances and coalitions appear to be thoroughly admissible and desirable. However, contenting oneself with the multiplicity of approaches carries no value in itself. As always, the supreme goal is looking for such viewpoints and methodologies which offer most chance of comprehending the nature of the landscape experience and solving the fundamental problems arising from the impact on the environment and landscape. Given my research perspective, the crucial issues include:

- The determination of the biological conditioning lying behind our preferences for landscape and its evaluations. It was probably Steven Pinker who stated that it is a disgrace we erect buildings and implement urban development plans of such a grand scale knowing so little about the biological demands and needs of human beings. Here, it would also be interesting to examine how, in the course of that process, one creates an architecture of community, to use Léon Krier's term, an architecture encompassing other people as well as plants, animals, and other organisms. Resolving these issues requires an alliance between representatives of biology, ecology, environmental psychology and environmental aesthetics.

- The experience of settling in versus alienation in the context of habitation practices (landscape). As Richard Sennett argues, classic Roman architecture played a stabilizing role in a world shaken with continual political turmoil. Just as the emphasis on settling in in landscape entails the danger of ossification 
and preservation in inertia, so intensifying the forces which strive to make "all that is solid melt into air"-in other words yielding to the ceaseless pressure of modernization which brings about successive watersheds and revolutions in methods of production, the organization of labour, art, culture and in human life-increase the risk of alienation. In this case, Lyotard's concept of scapeland is an interesting solution. One should hone the skill of looking at landscape from the position of a foreigner, a perspective in which things are no longer so familiar and obvious. The aim of such an approach is neither to fuel escapist tendencies nor to seek fulfilment in endless wanderings in the cemeteries of damaged objects and symbols; on the contrary, a more proximate experience of landscape is called for, which means ever more numerous and varied encounters with others who, along with us, inhabit and co-create landscape. At the same time, it should be stressed that the 'other' does not denote only other people but also other living organisms. The fundamental problem consists in affording that kind of experience to inhabitants of cities, who usually perceive nature as something which exists beyond urban areas and is quite frequently reduced to a mere means to something else or just merchandise. Such issues are to be resolved by representatives of urban ecology, environmental psychology and philosophy.

- Experiencing and creating images of alien places (xenotopies). The key question is how we experience and create images of places/xenotopies. What are the forms and methods of their cultural consolidation and reproduction? The joint effort of humanistic geography, philosophy-especially philosophy with a phenomenological bias-and post-colonial studies constitutes the necessary elements of research strategies which can yield answers to the above questions.

4.

Landscape for the "viewer" continues today to be presented chiefly in visual categories-this tradition surviving especially in the perception of the everyday viewer; it is equated with a view which is either pleasing or not to the beholder. Thus, elements of nature become landscape when the observer does not turn to it guided by a practical purpose, but takes it in from a distance, unhurriedly surveying the emerging whole. This is how landscape tended to be understood from $18^{\text {th }}$-century aesthetics to Georg Simmel and Joachim Ritter. Even a multisensory approach to landscape seems to be a revolutionary achievement of our culture, as it undermines the long-established conviction of the superiority and primacy of vision, empowering the sense of smell for instance-a sense which makes light of the distance and solemnity characteristic of the visual bias. "There are perfumes fresh as children's flesh /Soft as oboes, green as meadows/And others, corrupted, rich, triumphant/Possessing the diffusion of infinite things/Like amber, musk, incense and 
aromatic resin/Chanting the delights of spirit and senses."-as Baudelaire wrote in Correspondences. Even if we learn more than just to look at landscape, learn to experience it via other senses, through touch, smell, the sensation of different temperatures or textures, it is likely to be merely the first stage of understanding and experiencing landscape. In this context, landscape education should above all develop our sensibility for landscape and teach us the importance of the surroundings in which we live. It is also vital to mould practical attitudes to landscape. It would be a good idea to follow Georges Perec in that respect and include "plant a tree (and see how it grows)" on a list of things to do before one dies. Thanks to the development of proxemics and environmental psychology, there are numerous studies which promote a better understanding of how variously structured space affects our behaviour. So concern for oneself also means solicitude for the quality of the surroundings. It should be noted that if the quality of space in the vicinity of one's dwelling is poor, it may offer little if any opportunity for establishing ampler and more elaborate social relationships. As Jan Gehl underlines, the optimal solution in designing or converting existing cities is to devise spaces in such a way as to create "connecting links" between what is private and public, areas which may serve increasingly diversified social functions. An example of an architectural solution of this kind is a cooperative residential development Tinggården where "the family has a living room; residences are organized around two communal spaces, the outdoor square and the indoor communal house; and finally, the entire residential complex is built up around a public main street in which a large community centre also is located. Family members meet in the living room, the inhabitants of the residential group meet in the group square, and residents from the entire neighbourhood meet on the main street." (Gehl 2009, 57) Therefore landscape education should not only teach how to shape our immediate surroundings and create ecological conditions enabling development of other organisms, but also make us aware that the quality of our lives depends on participation in varied social activities, to which we may be encouraged by well-designed semipublic and public places.

A landscape hike and walk, especially when supplemented with reliable knowledge of the natural world, are important components of landscape education, not only for children and adolescents, but in fact for persons of all ages. Still, a true adventure and an opportunity to enter into a more profound relationship with nature arises only when one learns actively, i.e. through action. Establishing a garden by one's school may be a good starting point. Here, one should learn from those who elevated the art of gardening to the status of an Olympic discipline-the English. Their determination in making the surroundings of their houses more beautiful is admirable and represents a kind of cultural heritage which is cherished and cultivated by emigrants. When an Englishman finds himself on French soil-as happened to the protagonist of a novel by Michael Sadler-and it turns out 
that the garden adjoining the house has been neglected to the extent that its earth resembles concrete, the gardening aficionado will not hesitate to use a pneumatic drill to break it up only to grow a garden there, much to the growing astonishment of his neighbours. Sadler argues that even such a simple action as digging has its social even historical dimension, being a profoundly atavistic act: "When you sink the fork into the earth, you rediscover a primitive, long-forgotten rhythm." (Sadler 2011, 51) It establishes a link with our ancestors who, driven by need and curiosity, began to cultivate the soil. Thus, the social dimension unfolds as by means of that activity we begin to take our "humble place in a long line of tillers." (Ibidem, 51) Lacking practical and social activity, landscape education becomes suspended in a vacuum, which is why it should first of all encompass content relating to arrangements of places and be sensitive to colours and hues of plants, their smells and texture, sounds, the structure of matter, the play of views, lights, and shadows. Secondly, landscape education should teach us how landscape functions at an ecosystem level, explain its structure, functions and interrelations between natural and human-made systems. The approach can also be taught on a small scale, using the example of a garden. There are gardens of steroids, where plants proudly flaunt their fine-grown and opulent shapes. Still, the approach of Ken Thompson's is more compelling, as he does not really look to horticultural literature for ideas for his gardens, but "takes inspiration from a broadly understood botany, ecology and natural sciences. In other words, from literature which does not attempt to control natural environment but only seeks to understand it." (Thompson 2010, 12) Thirdly and finally, in the course of landscape education one should acquire and extend one's knowledge about the social dimension of the functioning of human beings: about the creation of places of social interactions, establishing contacts, joint actions and experiences.

\section{$\star \star *$}

Landscape is one of those categories which span an entire spectrum of seeing and experiencing the world. There are "panoramic landscapes" as well as "microscopic" ones. Oak Trees, a painting by Thomas Hearn (ca. 1786), shows almost exclusively the fragments of spreading oaks; here, landscape is not subordinated to any broader compositional structure. Instead of an expansive landscape panorama, it is only the detail which counts for Hearn. As he focuses on it, the trees reveal all the opulence of shapes and forms, their individual, unique appearance and character. Their twisted, broken boughs and branches are accentuated almost obsessively. The wealth of the composition, owing to the many elements and details, makes the trees depicted in the painting appear nearly gigantic, leaving one with a tremendous impression. The sweeping breadth of classic landscape is replaced here with depth of perception. The scale of landscape components may be reduced at will. In a short story by Hermann Broch, a balcony adorned with red pelargoniums which 
glow from afar becomes an image of bourgeois life. It is a stable and stolid life, underlined by heavy curtains and furniture, yet it has been provided with an architectural feature (the balcony) thanks to which one can go outside to catch a breath of air at any moment. We see a scene akin to those from Edward Hopper's paintings: the protagonist goes out onto the balcony and, leaning against the wall of the building, looks upon the city and the dark green square and the trees growing there. Even smaller landscapes can be found. For instance, Tiny Taxonomy, a temporary garden presented in 2010 by Rosette Sarah Elkin during Jardin de Métis, featured tubes containing small mosses and lichens. Their stunning opulence is nothing short of enchanting. On the other hand, we have here a classic landscape showing a broad view of the scenery. The avant-garde have in this way demonstrated that there are new modes of depicting space which convey one's bond with the surroundings. Proclaiming the end of one-dimensional representations of reality and the liberation of art from the obligation of showing the world with photographic precision, artists of the avant-garde saw an opportunity to expand the scope for perceiving the world. According to Matyushin $(1998,121)$, thus far artists had worked "within the scope of vision circumscribed by a 140-degree angle", but time had come to go beyond those limitations. " $\mathrm{C} \mathrm{u} \mathrm{b}$ i s $\mathrm{m}$ and $\mathrm{f} \mathrm{u} \mathrm{t} \mathrm{u} \mathrm{r} \mathrm{i} \mathrm{s} \mathrm{m} \mathrm{[...]} \mathrm{present}$ what the ordinary eye does not see and does not register. By breaching planes and showing objects from a hitherto unknown side, artists expose the creative power of nature, which desires to show life to the fullest extent possible, that is as motion in all directions." (Ibidem, 132) This is just a step away from Michael Snow's La Région Centrale (1971), in which the camera captures landscape revolving through $360^{\circ}$. However, regardless of the scale in which landscape may be represented, its potency lies in the ability to create synthetic images conveying the varied and vital relations which link the human being with their surroundings. This indeed brings the poetic form into play. Therefore, as a conclusion, I would like to quote a poem by Stanisław Grochowiak, entitled Landscape.

That then is the earth, my Homeland

All that is eternal in me-from these cucumbers here

From those pale flowers plucked greedily

By skeleton-thin sparrows.

All that open up those landscapes in me

A horse with its hooves jutting out into the sky

A rose suddenly colossal like a cow

A dried-up windmill

A finally-from an upended bottle

One cravingly drinks the very last drop 


\section{And cries \\ Mary \\ Jesus \\ Mary \\ Jesus \\ Mary \\ Jesus \\ Mary.}

\section{Bibliography:}

Gehl, Jan. 2009. Życie między budynkami. Użytkowanie przestrzeni publicznych, translated by Marta A. Urbańska. Warszawa: Wydawnictwo RAM [English translation: Gehl, Jan. 2011. Life Between Buildings: Using Public Space, translated by Jo Koch. Washington: Island Press].

Matiuszyn, Mikhail. 1928. "Próba nowego odczucia przestrzeni" ["An Attempt at a New Sense of Space"]. In Andrzej Turowski, Między sztuką a komuną. Teksty awangardy rosyjskiej 1910-1932, 120-139. Kraków: Universitas

Sadler, Michael. 2011. Anglik na wsi. Życie w zapadtej dziurze we Francji, translated by Andrzej P. Zakrzewski. Bielsko Biała: Wydawnictwo Pascal [English original: Sadler, Michael. 2005. An Englishman à la Campagne: Life in Deepest France. London: Simon \& Shuster].

Thompson, Ken. 2010. Z uchem przy ziemi, czyli jak zrozumieć swój ogród, translated by Zbigniew A. Królicki. Poznań: Zysk i S-ka [English original: Thompson, Ken. 2008. An Ear to The Ground: Understanding Your Garden, London: Eden Project]. 